\title{
Design and Numerical Analysis of a Micro Gas Turbine Combustion Chamber
}

\author{
A. C. Mangra \\ Combustion Chambers and Unconventional Energies Laboratory \\ COMOTI National Research \& Development Institute for Gas Turbines \\ Bucharest, Romania \\ andreea.petcu@comoti.ro
}

\begin{abstract}
The interest in micro gas turbines has been steadily increasing. As a result, attention has been focused on obtaining optimal configurations for micro gas turbines depending on the applications in which they are used. This paper presents the CFD modeling results regarding an annular type combustion chamber, part of an $800 \mathrm{~N}$ micro gas turbine, predestined to equip a small scale multifunctional airplane. Two configurations have been taken into consideration and 3D RANS numerical simulations have been conducted with the use of the commercial software ANSYS CFX. The liquid fuel droplets were modeled by the particle transport model, which tracks the particles in a Lagrangian way. An initial fuel droplet diameter of $500 \mu \mathrm{m}$ has been imposed. The numerical results obtained are encouraging. The flame was developed in the central area of the fire tube, its walls thus not being subjected to high temperatures. Also, the maximum temperatures were obtained in the primary zone of the fire tube. The temperature then decreased in the fire tube's secondary zone and dilution zone. The numerical results will be validated by conducting combustion tests on a testing rig which will be developed inside the institute's Combustion Chamber Laboratory.
\end{abstract}

\section{Keywords-CFD; combustion chamber; jet A; vaporizers}

\section{INTRODUCTION}

Micro gas turbines are smaller-scale versions of gas turbines used in aviation or various cogenerative applications, with power output ranging from $30 \mathrm{~kW}$ to $200 \mathrm{~kW}$. Micro gas turbines are used to generate power in Auxiliary Power Units (APUs), backup generators, and other standby electricalgeneration needs. They are also commonly used in propulsion systems for Unmanned Aerial Vehicles (UAVs) [1,2]. Micro gas turbines usually consist of a single-stage compressor connected through a shaft to a single-stage turbine. The combustion chamber is of annular type, in order to reduce the overall dimensions $[1,2]$. The scaling down of gas turbine technology impacts negatively the heat and combustion processes which reduce the turbine power output and efficiency. Hence, micro gas turbines often operate at very high shaft speeds (up to 100000rpm). Micro gas turbines offer the advantages of compact size, low weight per unit power and multi-fuel capability [1, 2]. The first micro gas turbine for aviation applications has been developed by the French manufacturer JPX. Soon two other companies, AMT and Schreckling, have produced their own micro gas turbines [3].

In this paper, the results of CFD modeling regarding an annular type combustion chamber, part of a $800 \mathrm{~N}$ micro gas turbine destined to equip a small scale multifunctional airplane are presented. In the first stage, an annular type combustion chamber equipped with 8 pressure-swirl injectors has been proposed. The numerical investigation results are presented in [3]. Although the numerical results were encouraging, the manufacturing of injectors small enough to fit in the available space is problematic. Thus, in the second stage the use of vaporizers instead of injectors was proposed. In this paper, two combustion chamber configurations are presented which have been taken into consideration. Both configurations are equipped with 16 vaporizers. The fuel is sprayed from the fuel supply ramp into the vaporizing tubes which are positioned inside the fire tube. These tubes are heated by combustion and thus the fuel droplets inside them vaporize before passing into the fire tube. Inside the fire tube, the fuel vapors are mixed with pressurized air received from the compressor. The reacting mixture thus obtained is burned, transforming the fuel's chemical energy into heat. The resulted hot exhaust gases expand in the turbine producing mechanical work.

The fire tube is divided into three zones: the primary zone, the secondary zone and the dilution zone $[4,5]$. The main function of the primary zone is to anchor the flame and provide sufficient time, temperature, and turbulence to achieve complete combustion of the fuel-air mixture. In the primary zone, a recirculation zone is created to ensure flame stability and to entrain a portion of the hot combustion gases in order to provide continuous ignition to the incoming fuel-air mixture. In the secondary zone, the temperature is dropped to an intermediate level by the addition of air. This allows further combustion of $\mathrm{CO}$ and other Unburned Hydrocarbons (UHC) resulting from the primary zone. The role of the dilution zone is to admit the remaining air and to provide an exhaust gases stream with a temperature distribution that is acceptable to the turbine $[4,5]$.

Over the years CFD techniques have proven useful in designing different component parts of a gas turbine [6, 7], including the combustion chamber [8-16]. However, the numerical simulation of the complex phenomena which take 
place inside the combustion chamber is still problematic. The interaction turbulence - combustion process has to be modeled. In the given case, in comparison with other research works in which the fuel was considered in gaseous state $[8,9,13,15$, 16], a liquid fuel, Jet A, was used. This is a further complication of the processes which take place inside the combustion chamber. The atomization and vaporization of the liquid fuel have also been simulated. The use of vaporizers instead of pressure-swirl injectors [14] is another complication. In this case, the heat transfer between the hot gases inside the fire tube and the vaporizers' walls has been taken into consideration and modeled. Given all the above, the article brings a contribution to the field of designing combustion chambers using CFD techniques.

\section{NUMERICAL SIMULATION SETTING}

In order to develop the new combustion chamber, a 3D steady RANS numerical integration of the Navier-Stokes equations has been carried out using the commercial software ANSYS CFX. The computational domain is composed of the combustion chamber, starting from the compressor's stator exit and ending at the turbine stator entrance. The data presented in Table I was the starting point for developing the new combustion chamber.

TABLE I. INITIAL DATA

\begin{tabular}{|c|c|c|}
\hline Parameter & Value & Unit \\
\hline Air mass flow & 1.4 & $\mathrm{~kg} / \mathrm{s}$ \\
\hline$P_{2}$ & 476201 & $\mathrm{~Pa}$ \\
\hline$T_{2}$ & 481.452 & $\mathrm{~K}$ \\
\hline Compressor exit flow angle & -18 & $\circ$ \\
\hline$T_{3 \text { calc. }}$ & 1173 & $\mathrm{~K}$ \\
\hline Fuel mass flow & 0.0274 & $\mathrm{~kg} / \mathrm{s}$ \\
\hline
\end{tabular}

\section{A. Geometry and Mesh}

In Figure 1 the two proposed combustion chamber configurations are presented. Starting from these geometries, unstructured type computation grids (Figure 2) have been generated using ICEM CFD. The mesh has been refined in the zone of the vaporizers and in the fire tube's primary zone.

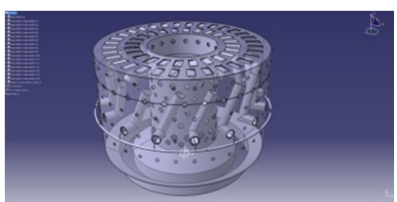

(a)

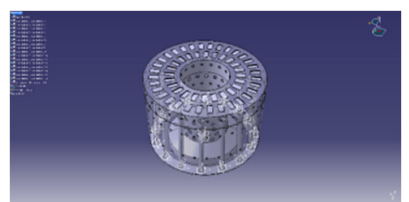

(b)
Fig. 1. The proposed combustion chamber configurations: (a) configuration 1 , (b) configuration 2 .

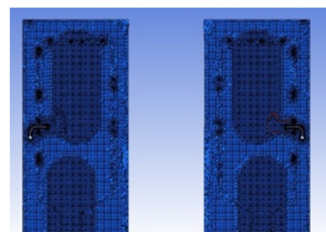

(a)

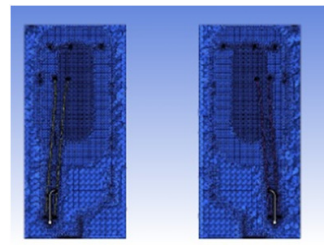

(b)
Fig. 2. The proposed combustion chamber configurations: (a) configuration 1 , (b) configuration 2 .
In both configurations, the computational domain is composed of a fluid body and 16 solid bodies representing the 16 vaporizers. Thus, the thickness of the vaporizer walls has been taken into consideration. This was necessary in order to be able to simulate the conductive heat transfer taking place inside the vaporizers walls. The grid area-averaged $y+$ value for wall regions of importance, like the vaporizer walls, is 80 and for less important walls is 150 . At this point, the interest has been more on the gases mixing inside the fire tube, than on the forces acting on the fire tube walls.

\section{B. Boundary Conditions}

The reference pressure has been set to 1 bar. At the air inlet a relative total pressure of 3.76201 bars and a total temperature of $481.452 \mathrm{~K}$ have been imposed. Also, a flow angle of $-18^{\circ}$ has been taken into consideration. Total mass flow of $1.4274 \mathrm{~kg} / \mathrm{s}$, representing the air mass flow $(1.4 \mathrm{~kg} / \mathrm{s})$ plus the fuel mass flow $(0.0274 \mathrm{~kg} / \mathrm{s})$, has been imposed at the outlet. The fuel is introduced in the computational domain through 16 surfaces of $0.6 \mathrm{~mm}$, representing the outlet of the fuel supply ramp, one for each vaporizer, as seen in Figure 3. The morphology option selected for the fuel is Particle Transport Fluid. The liquid fuel droplets are modeled by the particle transport model, which tracks the particles in a Lagrangian way. An initial fuel droplet diameter of $500 \mu \mathrm{m}$ has been imposed. Fuel mass flows corresponding to each vaporizer of $0.0017125 \mathrm{~kg} / \mathrm{s}$ and fuel temperature of $288 \mathrm{~K}$ have been set. The fuel droplets atomization process has been modelled using the $\mathrm{CAB}$ (Cascade Atomization Break-up) model, available in the ANSYS library. The fuel droplets vaporization process has been modeled using the Liquid Evaporation Model available in ANSYS library.

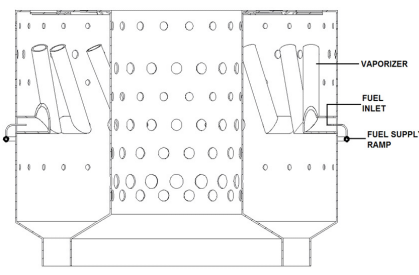

(a)

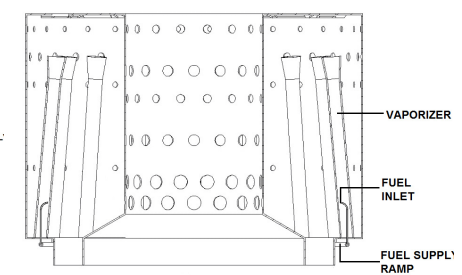

(b)
Fig. 3. Fuel inlet: (a) configuration 1, (b) configuration 2.

A RANS type turbulence model has been chosen, namely, the $k-\varepsilon$ model, which is a numerically stable and robust model and very popular in the realization of technical applications and numerical simulations. Along with this turbulence model, the scalable wall function formulation developed by ANSYS CFX has been used. The chosen combustion model has been the Eddy Dissipation Model (EDM), based on a two-step keroseneair reaction mechanism, imported from the ANSYS library, which also takes into consideration the formation of NO. A simple reaction mechanism has been chosen because the pollutant emission level has not been of interest at this point. The popular EDM model has been chosen because of its simplicity and robust performance in predicting turbulent reacting flows. In the numerical simulations the heat transfer through conduction inside the vaporizers' walls and the heat 
transfer by convection have been taken into consideration. The fire tube walls have been considered adiabatic.

\section{RESULTS}

The total relative pressure field on a longitudinal plane through the fire tube is presented in Figure 4. The average total pressure along the fire tube has been monitored in order to better understand the phenomena that take place inside the fire tube during the combustion process (Figure 5). In Figure 5, a normal behavior of the total pressure can be observed inside the fire tube. The points represent the mean values of the total pressure on traverse planes at different values of the $z$ coordinate along the fire tube. The total pressure decreases from a maximum value in the primary zone of the fire tube, to a minimum at the fire tube exit.

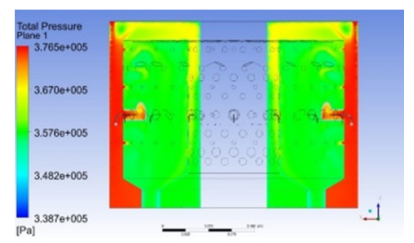

(a)

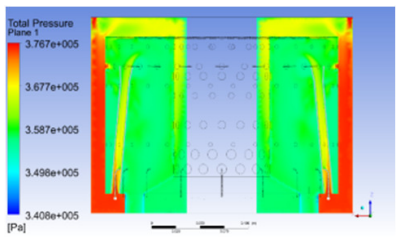

(b)
Fig. 4. Total relative pressure field on a fire tube longitudinal plane: (a) configuration 1 , (b) configuration 2 .

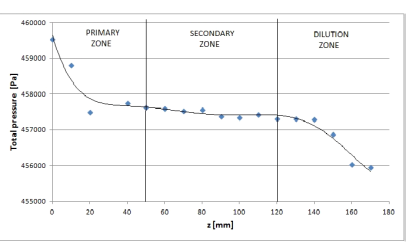

(a)

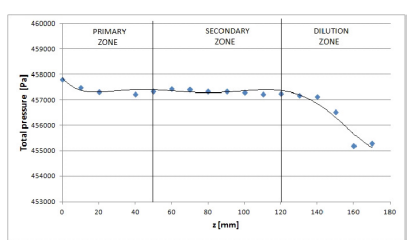

(b)
Fig. 5. Average total relative pressure along the fire tube: (a) configuration 1 , (b) configuration 2 .

In Figures 6-7 the flame developed inside the fire tube can be observed to not exceed its length. The flame was developed in the central area of the fire tube, its walls not being subjected to high temperatures. In configuration 1 , the maximum temperatures have been obtained in the primary zone of the fire tube. In configuration 2 , temperatures above $2000 \mathrm{~K}$ have also been obtained in the fire tube intermediary zone.

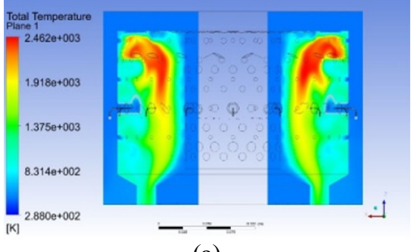

(a)

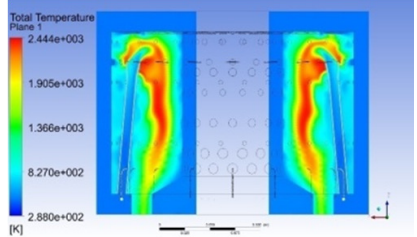

(b)
Fig. 6. Total temperature field on the fire tube longitudinal plane: (a) configuration 1, (b) configuration 2.

From Figure 8 the normal behavior of the total temperature inside the fire tube can be observed. The points represent the mean values of the total temperature on traverse planes at different values of the $z$ coordinate along the fire tube. The temperature rises in the primary zone of the fire tube, as the combustion reaction takes place, reaching a maximum. The temperature then decreases in the secondary zone and the dilution zone of the fire tube. This is achieved by introducing a larger quantity of air through holes placed on the fire tube walls. However, it is observed that the average temperature in the intermediary zone of the fire tube is higher in the case of configuration 2 compared to configuration 1 . This is consistent with the results shown in Figures 6-7

$1800 \mathrm{~K}$ isosurface
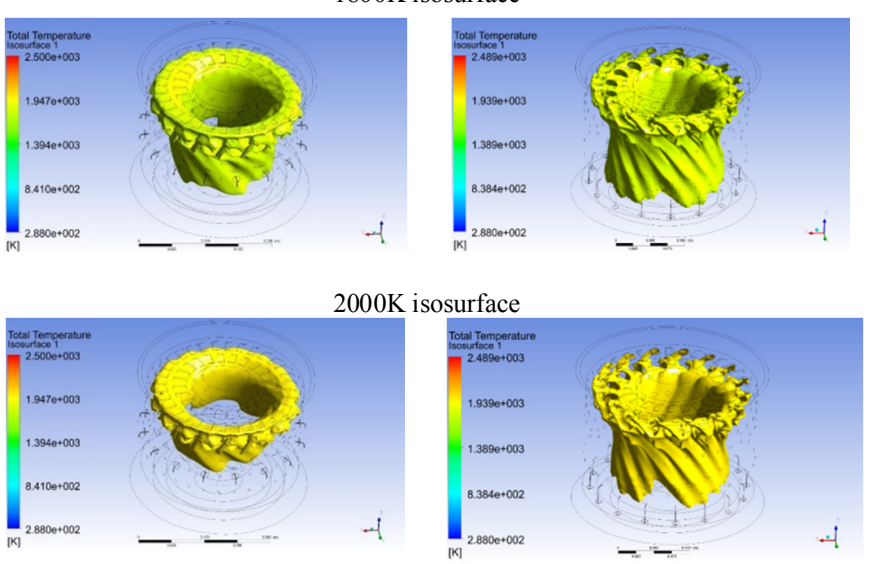

$2200 \mathrm{~K}$ isosurface

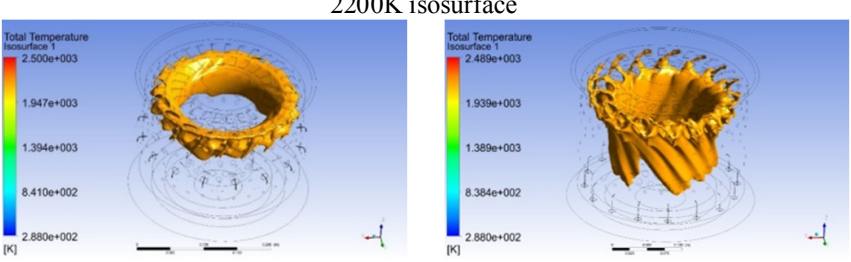

$2400 \mathrm{~K}$ isosurface

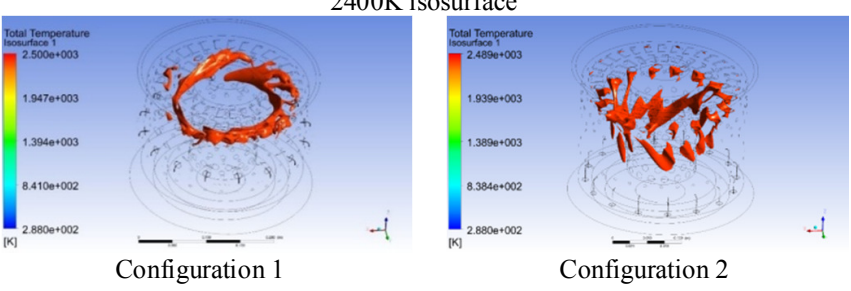

Fig. 7. Total temperature isosurfaces

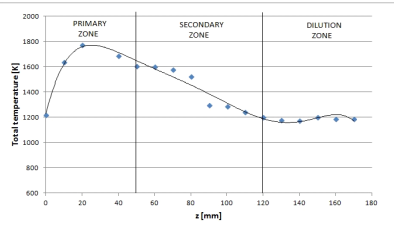

(a)

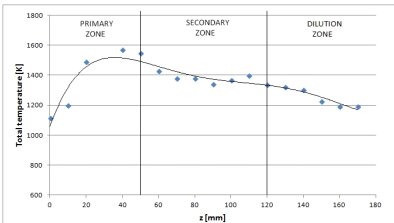

(b)
Fig. 8. The average total temperature along the fire tube: (a) configuration 1 , (b) configuration 2 .

The fuel droplets trajectories and mean diameter distribution are shown in Figure 9. A better swirling of the kerosene droplets in the case of configuration 1 is observed, due to the vaporizers shape and positioning. This favors a more frequent collision of the droplets with the vaporizers' walls, 
which leads to a more efficient vaporization process. As the vaporization process takes place, the fuel droplets' diameter decreases from the initial value of $500 \mu \mathrm{m}$ to 0 . In Figure 10, the vaporizers' wall temperature is presented. A better heating of the vaporizers' walls is observed in the case of configuration 1. This favors a better vaporization of the fuel droplets. Due to their shape and positioning, the vaporizers in configuration 1 are better immersed in the hot central zone of the fire tube. In configuration 2, the flame is developed mainly between the vaporizer and the fire tube inner wall, as can be seen in Figure $6(\mathrm{~b})$. Thus, only a small portion of the vaporizers is immersed in the hot central zone of the fire tube. This led to less efficient vaporizer walls heating, as can be seen from Figure10(b).

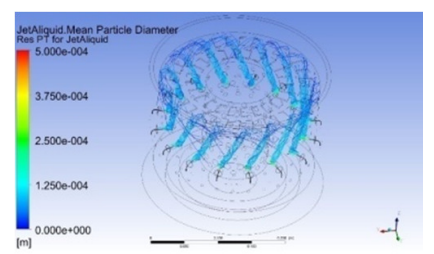

(a)

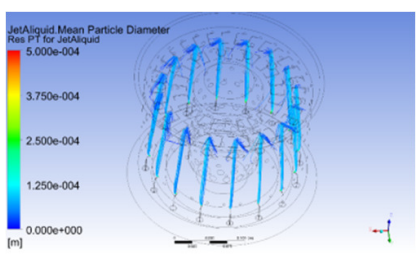

(b)
Fig. 9. Jet A droplets trajetories and droplets mean diameter distribution: (a) configuration $1,($ b) configuration 2 .

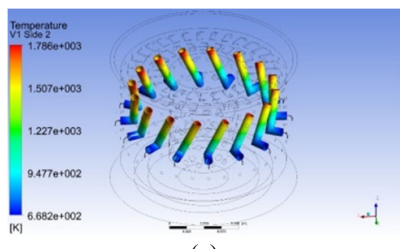

(a)

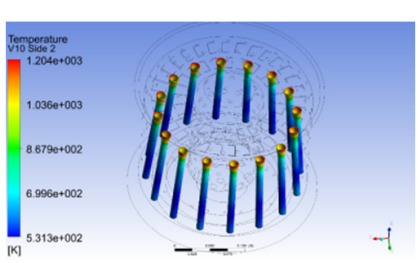

(b)
Fig. 10. Vaporizer wall temperature: (a) configuration 1, (b) configuration 2.

In Figures 11-13 the total pressure outlet field, the total temperature outlet field, and the velocity outlet field are presented. Ideally, a uniform pressure/temperature/velocity field at the combustion chamber exit is desired, which is impossible to obtain. From Figure 11 it can be observed that a more uniform pressure field has been obtained for configuration 1. Also, in the case of the temperature field, the obtained results in the case of configuration 1 are better, as can be seen from Figure 12. The maximum temperature at the combustion chamber outlet in configuration $1(1464 \mathrm{~K})$ is lower than in configuration $2(1680 \mathrm{~K})$. This is important in order to not subject the turbine to high temperatures during the micro gas turbine operation. Regarding the velocity field, the differences between the two configurations are not significant, as can be seen from Figure 13.

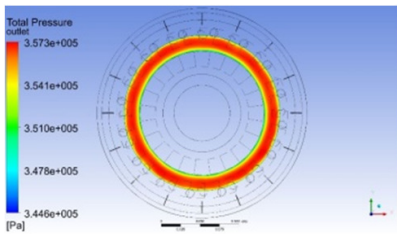

(a)

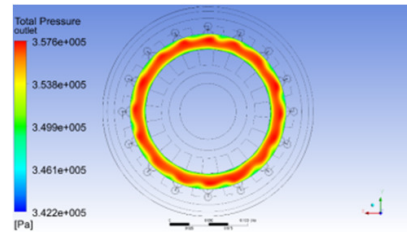

(b)
Fig. 11. Total relative pressure outlet field: (a) configuration 1, (b) configuration 2 .

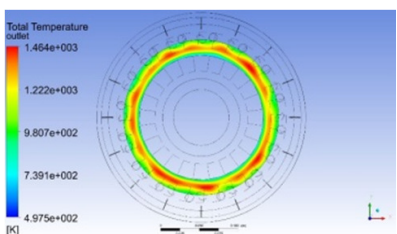

(a)

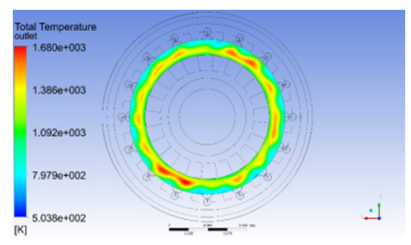

(b)
Fig. 12. Total temperature outlet field: (a) configuration 1, (b) configuration 2
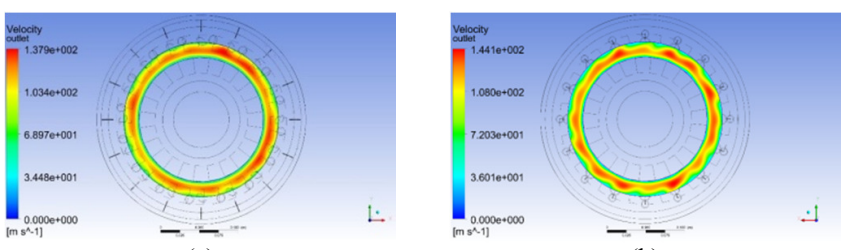

(a)

(b)

Fig. 13. Velocity outlet field: (a) configuration 1, (b) configuration 2.

In Table II the average values of the operating parameters at the combustion chamber exit are presented.

TABLE II. OPERATING PARAMETERS' AVERAGE VALUES AT THE COMBUSTION CHAMBER EXIT

\begin{tabular}{|c|c|c|c|}
\hline Parameter & Configuration 1 & Configuration 2 & Unit \\
\hline$P_{3}$ & 455938 & 455293 & $\mathrm{~Pa}$ \\
\hline Pres. loss $=\frac{P_{2}-P_{3}}{P_{2}} \cdot 100$ & 4.2 & 4.4 & $\%$ \\
\hline$T_{3}$ & 1187 & 1189 & $\mathrm{~K}$ \\
\hline$\frac{T_{3}-T_{3 \text { calc }}}{T_{3 \text { calc }}} 100$ & 1.2 & 1.3 & $\%$ \\
\hline$v_{3}$ & 104.5 & 104 & $\mathrm{~m} / \mathrm{s}$ \\
\hline Exit flow angle & -16.6 & -12.8 & $\circ$ \\
\hline
\end{tabular}

\section{CONCLUSIONS}

The CFD modeling results regarding an annular type combustion chamber, part of a $800 \mathrm{~N}$ micro gas turbine designed to equip a small scale multifunctional airplane have been presented in this paper. The manufacturing of pressure swirl injectors small enough to fit in the available space is problematic. Thus replacing the pressure swirl injectors with vaporizers has been taken into consideration. Two combustion chamber configurations, both with 16 vaporizers, have been analyzed using CFD modeling. The operating parameters average values at the combustion chamber exit, presented in Table II, are very similar for the two proposed combustion chamber configurations. However, in configuration 1 the maximum temperatures have been obtained in the fire tube's primary zone, while in configuration 2 , temperatures over $2000 \mathrm{~K}$ have been also obtained in the fire tube's secondary zone. The combustion chamber outlet total temperature is more uniform in configuration 1 than in configuration 2. Higher temperature at the combustion chamber outlet was reported for configuration 1 than for configuration 2 . Thus it was decided to go along with configuration 1 .

The next step is the manufacturing of the combustion chamber assembly. Then the experimental procedure will begin and the numerical results will be compared with the experimental ones. 


\section{ACKNOWLEDGMENT}

This work was carried out within "NUCLEU" Program, supported by the Romanian Minister of Research and Innovation, project number PN 19050105

\section{REFERENCES}

[1] P. Breeze, "Chapter 8 - Microturbines," in Gas-Turbine Power Generation, P. Breeze, Ed. Academic Press, 2016, pp. 77-82.

[2] M. A. R. do Nascimento et al., "Micro Gas Turbine Engine: A Review," Progress in Gas Turbine Performance, Jun. 2013, https://doi.org/ $10.5772 / 54444$.

[3] J. Parente, G. Mori, V. V. Anisimov, and G. Croce, "Micro Gas Turbine Combustion Chamber Design and CFD Analysis," presented at the ASME Turbo Expo 2004: Power for Land, Sea, and Air, Nov. 2008, pp. 787-796, https://doi.org/10.1115/GT2004-54247.

[4] A. H. Lefebvre and D. R. Ballal, Gas Turbine Combustion: Alternative Fuels and Emissions, Third Edition, 3rd Edition. Boca Raton: CRC Press, 2010.

[5] A. H. Lefebvre and V. G. McDonell, Atomization and Sprays, 2nd ed. Boca Raton, FL: CRC Press, 2017.

[6] M. W. Khalid and M. Ahsan, "Computational Fluid Dynamics Analysis of Compressible Flow Through a Converging-Diverging Nozzle using the k- $\varepsilon$ Turbulence Model," Engineering, Technology \& Applied Science Research, vol. 10, no. 1, pp. 5180-5185, Feb. 2020, https://doi.org/ 10.48084/etasr.3140.

[7] M. U. Sohail, M. Hassan, S. H. R. Hamdani, and K. Pervez, "Effects of Ambient Temperature on the Performance of Turbofan Transonic Compressor by CFD Analysis and Artificial Neural Networks," Engineering, Technology \& Applied Science Research, vol. 9, no. 5, pp. 4640-4648, Oct. 2019, https://doi.org/10.48084/etasr.2998.

[8] K. Sreenivasarao and S. K. Bhatti, "CFD Modeling Of An Aero Gas Turbine Combustor For A Small Gas Turbine Engine," International Journal of Engineering Research \& Technology, vol. 2, no. 1, Jan. 2013.

[9] N. L. Pradhani, A. Rajesh, and M. S. Ganesh Prasad, "CFD Analysis on Can-Type Combustor and Variation of Air Injection Angle under Typical Engine Condition," Journal of Aeronautics \& Aerospace Engineering, vol. 5, no. 2, 2016, Art. no. 1000170, https://doi.org/ 10.4172/2168-9792.1000170.

[10] R. Marudhappan, U. Chandrasekhar, and K. Hemachandra Reddy, "No reaction flow analysis of aero-derivative annular combustor of a turbo shaft engine," International Journal of Advanced Research in Engineering and Technology, vol. 9, no. 4, pp. 102-112, Aug. 2018.

[11] L. O. Rodrigues, H. S. Alencar, M. A. R. Nascimento, and O. J. Venturini, "Aerodynamic Analysis Using CFD for Gas Turbine Combustion Chamber," presented at the ASME 2007 Power Conference, Apr. 2009, https://doi.org/10.1115/POWER2007-22181.

[12] T. Suchocki, P. Lampart, and P. Klonowicz, "Numerical investigation of a GTM-140 turbojet engine," Open Engineering, vol. 1, no. open-issue, pp. 478-484, 2015, https://doi.org/10.1515/eng-2015-0053.

[13] F. Fuchs, V. Meidinger, N. Neuburger, T. Reiter, M. Zündel, and A. Hupfer, "Challenges in designing very small jet engines - fuel distribution and atomization," in 16th International Symposium on Transport Phenomena and Dynamics of Rotating Machinery, Honolulu, HAW, Apr. 2016.

[14] R. Calabria, F. Chiariello, P. Massoli, and F. Reale, "Numerical Study of a Micro Gas Turbine Fed by Liquid Fuels: Potentialities and Critical Issues," Energy Procedia, vol. 81, pp. 1131-1142, Dec. 2015, https://doi.org/10.1016/j.egypro.2015.12.138.

[15] E. Prasetyo, R. Hermawan, A. L. Putra, and D. L. Zariatin, "Fluid flow analysis of micro gas turbine using computational fluid dynamics (CFD)," in Proceedings of the 4rth IRSTC 2017, 2017.

[16] H. A. Bhimgade, C. A. Mahatme, P. S. Barve, and N. D. Gedam, "CFD approach as design optimization for gas turbine tubular combustor," Journal of Research in Engineering and Applied Sciences, vol. 01, no. 02, pp. 92-102, Apr. 2016.

\section{AUTHORS PROFILE}

Andreea Cristina Mangra was born in 1986. Sha tooke her $\mathrm{PhD}$ in Aerospace Engineering, in 2016 at Politehnica University of Bucharest and is a scientific researcher since 2010, carrying out experimental activities and numerical investigations of the combustion process in the Combustion Chamber Laboratory of the COMOTI National Research \& Development Institute for Gas Turbines, Bucharest, Romania. She is experienced in 3D design using CATIA and in CFD numerical simulations using ANSYS CFX. She is the author of 20 scientific papers published in peer reviewed journals (WOS and BDI) and conference proceedings and a co-author of 3 chapters of scientific books and of 2 patents in the field of combustion. 